\title{
Feasibility of developing Children's Pill School within a UK hospital
}

Asia N Rashed ${ }^{1,2 *}$ (https://orcid.org/0000-0003-1313-0915), David Terry ${ }^{3}$, Andy Fox ${ }^{4}$, Nanna Christiansen ${ }^{1}$, Stephen Tomlin ${ }^{5}$

1. Evelina Pharmacy, Evelina London Children's Hospital, Guy's and St Thomas' NHS Foundation Trust, London, UK

2. Institute of Pharmaceutical Science, King's College London, London, UK

3. Academic Practice Unit, Life \& Health Sciences, Aston University, UK

4. Southampton University Hospital NHS Foundation Trust, Southampton, UK

5. Great Ormond Street Hospital for Children NHS Foundation Trust, London, UK

*Correspondence author

Dr Asia N Rashed

King's College London

150 Stamford Street

London SE1 9NH

Email: asia.rashed@kcl.ac.uk

Word count: 1194 (excluding title page, abstract, references and tables)

Keywords: Children, Pill School, tablets, pills, swallowing training, feasibility, hospital 


\section{ABSTRACT}

Objective: We assessed the feasibility of introducing an intervention (Children's Pill School - PS) within a UK hospital to provide swallowing training for children; identified the proportion of children who can be switched from oral-liquid medicines to pills; and assessed child/parents' opinions about the PS training.

Methods 30 inpatient children [aged 3-18 years; taking oral-liquid medicines; their liquid medications assessed suitable for switching to pills; can (and their parents) speak/understand English] were included. Training sessions were delivered using hard sweets of different sizes.

Results $87 \%$ (26) of children successfully learned how to swallow pills after one training-session (mean duration 14.5 minutes), and 92\% (24) were discharged on pills. 75 prescribed oral-liquid medications were deemed suitable for switching to pills. Of these, $89 \%$ (67) were switched successfully.

Conclusion Children as young as 3 years were successful in swallowing pills after training. Providing children PS training-session within hospital is feasible and acceptable to children and their parents. 


\section{INTRODUCTION}

Oral liquid formulations of medicines are most frequently used for children but have numerous disadvantages including: poor stability, unpleasant taste and higher cost than tablets/capsules (hereafter referred to as pills).[1] Pills also have better stability, uniform presentation and may improve adherence. The European medicines agency advises that adequate training could improve tablet acceptability in children.[2] Pill swallowing training has the potential to enable young children to safely take pills. The most appropriate way of delivering this training has not yet been identified.

This study aimed to: assess the feasibility of introducing an intervention called PS, within UK hospitals; train children how to swallow pills; identify the proportion of children who can be swapped from liquid medicines to pills; and assess child/parents' opinions regarding training.

\section{METHODS}

Prospective feasibility study at the Evelina London Children's Hospital (ELCH), UK, with training sessions conducted at the bedside or play area between February-October 2019. Training techniques were collated from literature [3] supported by a pre-study locally developed information booklet for clinicians. Local teachers, a hospital pharmacist and a research nurse, were trained by an experienced PS teacher.

Participant inclusion criteria: 3 to 18 years, taking oral liquid/manipulated solid medicines (e.g. crushed), medication regime assessed as suitable for pills (paediatric pharmacist), suitable dose by whole or halved or quartered pill, ability to understand English.

Exclusion criteria: significant developmental delay; visual, hearing, motor or learning disabilities; diagnosed with clinical swallowing difficulties; and children not eating, or drinking.

Participant information sheets were provided, and signed consent obtained prior to a training session on the day of enrolment or before discharge. The session ( $<30$ minutes) ensured that parents 
understood the swallowing technique taught to their child to support continuity and was attended by the ward pharmacist. The session was delivered using hard sweets (Supplementary Table 1) starting from the smallest size and gradually increasing. Children/parents were invited to describe their experiences of taking liquids and any previous attempts to swallow pills. Taught techniques were individualised to the participant - see appendix A. If pill swallowing was achieved, and following parental consent, the prescriber changed inpatient medications and discharge forms to pills. Child's ability to swallow pills was confirmed by taking one dose of their actual solid medication while they were in hospital.

Only one training session was provided to each participant.

Follow-up was conducted by teacher phone calls at +2 days, +1 month and +6 months post-discharge, and recorded using a semi-structured questionnaire. Follow-up explored the child's ongoing confidence to swallow pills, ongoing medication formulations and medication administration issues. Descriptive analysis was undertaken using Stata 15 software. Content analysis on session notes were facilitated using NVivo 12 software.

\section{Ethical approval}

This study was approved by the Health Research Authority and Care Research Wales (Reference number 18/SC/0285).

\section{RESULTS}

30 participants (range 3 to 14 years, mean $7.8 \pm 3.3$ years, (Supplementary Table 2). $87 \%$ ( $n=26$ ) succeeded in swallowing pills after a single session (range 8 to 30 minutes, mean $14.5 \pm 5.8$ minutes). Typically, five different sweet sizes were swallowed per child.

50\% ( $n=15)$ tilted head back and 47\% ( $n=14)$ looked straight ahead (Supplementary Table 3). 57\% $(n=17)$ preferred plain water in everyday cups. All participants refused a special pill-cup. Nine children aged 3 to 5 years and 12 children aged 6 to 11 years successfully learned to swallow pills (no statistically significant difference between age groups). Younger children were assessed as being more 
enthusiastic about the training and less concerned about incremental sweet size (Table 1). $92 \%$ ( $n=24)$ were discharged on pills. Of the remaining two children, in one case parents refused discharge medication as pills although the child demonstrated their ability to take them, and the second child was unable to swallow $500 \mathrm{mg}$ amoxicillin capsules.

Table 1 Frequency of different sweet sizes used by age groups

\begin{tabular}{|c|c|c|c|c|}
\hline Sweet & Sweet image & $\begin{array}{c}\text { 3-5 years } \\
\mathrm{n}(\% \text { out of } 12) *\end{array}$ & $\begin{array}{c}\text { 6-11 years } \\
n(\% \text { out of } 13) *\end{array}$ & $\begin{array}{c}12-18 \text { years } \\
n(\% \text { out of } 5)^{*}\end{array}$ \\
\hline $\begin{array}{l}\text { Popping candy (Cake angels) } \\
\text { (approx. } 1.0 \mathrm{~cm} \text { ) }\end{array}$ & $\equiv$ & $2(16.7)$ & $7(53.8)$ & $2(40.0)$ \\
\hline $\begin{array}{l}\text { Gold balls cake decoration } \\
\text { (approx. } 0.3 \mathrm{~cm} \text { ) }\end{array}$ & & $9(75.0)$ & $12(92.3)$ & $5(100.0)$ \\
\hline $\begin{array}{l}\text { Jelly Belly beans } \\
\text { (approx. } 1.7 \times 0.9 \mathrm{~cm} \text { ) }\end{array}$ & 878 & $2(16.7)$ & $6(46.1)$ & - \\
\hline $\begin{array}{l}\text { Mike\& Ike candy fruits } \\
\text { (approx. } 2.3 \times 0.9 \mathrm{~cm} \text { ) }\end{array}$ & 29 markente & $1(8.3)$ & $3(23.1)$ & - \\
\hline $\begin{array}{l}\text { Millions } \\
\text { (approx. } 0.7 \mathrm{~cm} \text { ) }\end{array}$ & $=$ & $5(41.7)$ & $7(53.8)$ & $1(20.0)$ \\
\hline $\begin{array}{l}\text { Nerds candies } \\
\text { (approx. } 0.3 \times 0.7 \mathrm{~cm} \text { ) }\end{array}$ & लerds & $2(16.7)$ & $3(23.1)$ & $1(20.0)$ \\
\hline $\begin{array}{l}\text { Silver balls cake decoration } \\
\text { (approx. } 0.5 \mathrm{~cm} \text { ) }\end{array}$ & $\mathrm{s}$ & $9(75.0)$ & $12(92.3)$ & $5(100.0)$ \\
\hline $\begin{array}{l}\text { Tic tac } \\
\text { (approx. } 0.6 \times 1.0 \mathrm{~cm} \text { ) }\end{array}$ & $\sqrt{25}$ & $8(66.7)$ & 11 (84.6) & $3(60.0)$ \\
\hline $\begin{array}{l}\text { Wacky monkey candies } \\
\text { (approx. } 0.3 \times 0.6 \mathrm{~cm} \text { ) }\end{array}$ & 6 & $5(41.7)$ & $4(30.8)$ & $4(80.0)$ \\
\hline
\end{tabular}

${ }^{*} \mathrm{n}=$ number of children in each age group. Number of children do not add up as one child swallowed more than one sweet. 
Admission medication included 103 prescribed liquids (median four per patient), of which 75 were assessed as suitable for switching to pills. Of these $89 \%$ ( $n=67 / 75)$ were switched successfully for the 24 children discharged on pills (median 3 per patient) (Table 2).

Table 2 List of medications switched to solid dosage forms post successful PS training session

\begin{tabular}{|c|c|c|}
\hline Medication & Pill image & $\begin{array}{l}\text { Frequency }(\% \\
\text { out of } 67)\end{array}$ \\
\hline Paracetamol 500 mg tablet & & $17(25.4)$ \\
\hline Ibuprofen $200 \mathrm{mg}$ tablet & & $7(10.4)$ \\
\hline Omeprazole 20 mg Capsule & 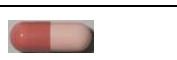 & $5(7.5)$ \\
\hline Aspirin $75 \mathrm{mg}$ tablet & $\mathcal{Y}$ & $4(6.0)$ \\
\hline Ondansetron $4 \mathrm{mg}$ tablet & OS & $4(6.0)$ \\
\hline $\begin{array}{l}\text { Morphine sulphate } 10 \mathrm{mg} \text { immediate } \\
\text { release tablet }\end{array}$ & & $4(6.0)$ \\
\hline Prednisolone $5 \mathrm{mg}$ tablet & & $3(4.5)$ \\
\hline Senna $7.5 \mathrm{mg}$ tablet & & $2(3.0)$ \\
\hline Chlorphenamine maleate $4 \mathrm{mg}$ tab & & $2(3.0)$ \\
\hline Clonidine HCL 100 mcg tablet & & $2(3.0)$ \\
\hline Ibuprofen $400 \mathrm{mg}$ tablet & & $2(3.0)$ \\
\hline Dihydrocodeine $30 \mathrm{mg}$ tablet & ) & $2(3.0)$ \\
\hline Lisinopril $2.5 \mathrm{mg}$ tablet & & $2(3.0)$ \\
\hline Clarithromycin $250 \mathrm{mg}$ tablet & 3 & $2(3.0)$ \\
\hline Prednisolone $25 \mathrm{mg}$ tablet & ( & $1(1.5)$ \\
\hline Bisacodyl $5 \mathrm{mg}$ tablet & & $1(1.5)$ \\
\hline Cetirizine $10 \mathrm{mg}$ tablet & $C$ & $1(.5)$ \\
\hline Ciprofloxacin $500 \mathrm{mg}$ tablet & 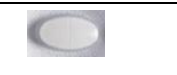 & $1(1.5)$ \\
\hline Co-amoxiclav $250 \mathrm{mg} / 125 \mathrm{mg}$ tablet & 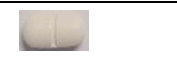 & $1(1.5)$ \\
\hline Furosemide $20 \mathrm{mg}$ tablet & $\mathcal{U}$ & $1(1.5)$ \\
\hline Lisinopril $5 \mathrm{mg}$ tab let & & $1(1.5)$ \\
\hline Phenoxymethylpenicillin $250 \mathrm{mg}$ tablet & $\exists$ & $1(1.5)$ \\
\hline Tacrolimus cap (Adoport) $0.5 \mathrm{mg}$ & $2=$ & $1(1.5)$ \\
\hline
\end{tabular}


All parents reported that medication taking had become easier during post training follow-up (Supplementary Table 4). $77 \%(n=23)$ of participants identified the main difficulty with liquid medication as being taste (Supplementary Figure 1).

All parents reported the benefit of pill school training. For parents had attempted to teach their child to swallow pills at home but all were unsuccessful. $87 \%(n=26)$ confirmed they did not know that young children could take pills. $87.5 \%(n=21)$ reported that training improve their child's confidence in taking medication. Parents became more confident in buying OTC medication in pill form. Training identified a medication-related anxiety in one patient which was successfully managed by psychologist intervention.

\section{DISCUSSION}

The training sessions proved to be effective with children as young as three years with over $90 \%$ of children being discharged on pills - participants ranged from 3 to 14 years. Children under 11 years were more enthusiastic than older children and acquired the skill easily; consistent with previous findings.[3] Parents consistently expressed surprise at their child's ability to swallow pills, but availability of pills needs healthcare professional input. Existing beliefs about the appropriate age to take pills may be usefully challenged by clinical staff.

Switching to pills may improve safety by reducing the potential for dosing errors, and make medication taking easier and support independence.[3-4] Improved adherence may result.

Parental engagement during the training session was considered important to confirm their acceptance of the child's ability to swallow pills and support medication choice in the future

This study was designed to prove the concept of providing PS training for children within UK hospitals, however using hospital costs for the drugs, swapping the 67 liquids medicines to pills for the 24 children on discharge would result in a potential saving of $£ 31,133$ each year ( $89 \%$ reduction in medication costs). Hospital costs are different to community costs. More prescribed liquids are 
specials compared to tablets. Thus, in the community the cost saving could even be higher. Similar costs saving resulted from switching to pills have also been reported previously.[5]

Limitations include no detailed assessment of cost saving, however there are known potentially large cost savings in switching to pills.[6] The impact of training on medication adherence was not investigated. The short-term risk of the sugar content of the sweets used in training are considered negligible, except for children unrelated restricted diets. Future research should address these limitations.

\section{CONCLUSIONS}

The high success rate of pill swallowing $(92 \%)$ demonstrates the utility of providing children with a single swallowing training session as part of routine clinical care. The study showed that children can be prescribed pills from 3 years of age, if they are provided with a swallowing training session. The PS initiative was acceptable to children and parents. PS has influenced the confidence of both child and parent positively in regard to taking/administering pills. Integrating a PS training session into routine paediatric care would increase children's access to medications by both increasing the availability of solid formulations and avoidance of unpalatable liquid formulations. As a consequently medication adherence may improve.

Acknowledgements: The authors thank participated children and their families and all nurses, ward pharmacists at Evelina London Children's hospital for their support with the study.

Contributors: ANR, ST, DT, and AF developed the concept and design of the study. ANR is responsible for the study, follow-up calls and data collection, data management and statistical analysis. ANR drafted the manuscript. ST, DT, and NC critically reviewed the manuscript draft. All co-authors reviewed and approved the final manuscript.

Funding: This study is funded by the Pharmacy Research UK and supported by the Evelina London Children's hospital (grant number: PRUK-2016-PG3-2-A). 
Competing interests: ANR was funded by the PRUK. ST, DT received fund for their contribution on the project. NC and AF have no competing interest to declare.

Patient consent for publication: Not required.

Data sharing statement: All relevant data are within the paper and its supporting information files. 


\section{What is already known on this topic}

- Evidence shows that children can swallow pills from age of 3 years, however, significant amounts of oral-liquid medicines are still being used in paediatric.

- No formal guidance for paediatric prescribers to consider pills instead of oral-liquids for children from an early age.

- There are no systematic swallowing training sessions established as an integrated part of the healthcare services available to children in the UK.

\section{What this study adds}

- The Pill School initiative providing a one-short training swallowing training session was effective and acceptable by children and their parents.

- Children as young as 3 years were able to learn the swallowing skills and switched to pills.

- Pill School service should be implemented in clinical settings to offer training to children and their parents before prescribing oral-liquids. 


\section{References}

1. Lopez FL, Ernest TB, Tuleu C, et al. Formulation approaches to pediatric oral drug delivery: benefits and limitations of current platforms. Expert Opin Drug Deliv 2015;12:1727-40.

2. EMA Committee for Medicinal Products for Human use (CHMP). Reflection paper on formulations of choice for the paediatric population. 2006. Available:

http://www.ema.europa.eu/docs/en GB/document library/Scientific guideline/2009/09/WC50000 3782.pdf. Accessed 05 May 2020 (accessed Oct 2020).

3. Patel A, Jacobsen L, Jhaveri R, et al. Effectiveness of Pediatric Pill Swallowing Interventions: A systematic review. Pediatrics 2015; 135:884-9.

4. Yin HS, Mendelsohn AL, Wolf MS, et al. Parents' medication administration errors: role of dosing instruments and health literacy. Arch Pediatr Adolesc Med 2010; 164:181-6.

5. Tse $Y$, Vasey N, Dua D, et al. The KidzMed project: teaching children to swallow tablet medication. Arc Dis Child 2019; 0:1-3.

6. Lajoinie A, Henin E, Kassai B, et al. Solid dosage forms availability in children: a cost saving investigation. Br J Clin Pharmacol 2014; 78:1080-89. 